\title{
Teaching
Methods
}

\section{Plant Madness: A Classroom Game Using Bracketology for Horticulture Plant Identification Courses}

\author{
Chad T. Miller ${ }^{1,2}$
}

ADDITIONAL INDEX wORDs. undergraduate education, woody plants, herbaceous plants, game-based learning, creativity

Summary. Plant Madness was a classroom activity developed and implemented for the Landscape Plants II identification course at Kansas State University. The game was modeled after the National Collegiate Athletic Association college basketball March Madness tournament and Bracketology. One activity objective was to provide students an opportunity to learn new and recent cultivars and plant species not specifically covered in the class curriculum. The activity also provided students opportunities to practice public speaking skills, an avenue to be creative, and simply have fun in class. In Plant Madness, each student randomly drew a plant from a hat and then students were randomly assigned tournament seed rankings (preliminary rankings). On specified game days, one student played against another student, each having 2 minutes of play. Student play varied, and consisted of defining different plant attributes, landscape appeal, and interesting facts, for example; or identifying the opposing student's plant's faults through riddles, poems, games, songs, or simply recitation. Referees (e.g., guest faculty, graduate students) reviewed student play and awarded points, and the student with the highest score advanced to the next round through the single-elimination tournament. A postactivity survey was administered [Spring 2016 and $2017(n=44)$ ] to obtain student feedback. When asked if the students liked the activity, it was nearly unanimous, $98 \%$ liked Plant Madness. Similarly, most students (93\%) self-reported the activity increased their awareness of new or recent plant cultivars. When asked to rate the activity compared with other class approaches for learning different plants based on a scale of 1 (excellent) to 5 (poor), the average rating was 1.8 . Students' average rating for their ability to be creative for Plant Madness was 1.8 ( $1=$ to a large extent, $5=$ not at all $)$. Ninety-five percent of the students recommended repeating the activity.

$\mathrm{T}$ The objective of horticulture plant identification courses is to assist students in learning many different plant species. There is a significant amount of information that can be disseminated in those courses. The HORT 375 Landscape Plants II course at Kansas State University (KSU) in Manhattan focuses primarily on learning common landscape plant genera and species, from woody plants to herbaceous plants.
Lecture-style teaching methods are common in college courses, including plant identification courses. Common feedback from some students regarding the identification courses is that learning plant after plant, as the semester progresses, can be boring and monotonous. This can be especially true after having already had the Landscape Plants I course the previous semester. A significant focus for the plant identification courses at KSU has been to implement diverse learning activities, including student-centered learning and active learning methods to encourage student engagement and diversify the typical plant identification course. Deeter (2003) reported positive student feedback from increased student-centered learning activity incorporation.

For several weeks during the spring academic semester, primarily March, many people, including students, are seemingly consumed with March Madness, the annual National Collegiate Athletic Association (NCAA) Division I men's and women's basketball tournament (Geiling, 2014; Wilco, 2019). With an understanding of Bracketology [an activity of predicting participants and outcomes of games in a sports tournament (e.g., the NCAA basketball tournament)], students fill out brackets and subsequently cheer for their favorite sports teams and players in the tournament. In the workplace, it has been reported that March Madness negatively affects workplace productivity, with employees spending upward of 6 paid hours focused on the tournament (Morris, 2018) and costs employers an estimated $\$ 1.9$ billion in wages (Bukszpan, 2015). However, reports also show that despite negative perceptions of March Madness, it can be beneficial to a company, providing workplace cohesiveness (Smith and Smith, 2011; Smith et al., 2011) in the long term. We are unaware of any reports quantifying positive or negative effects of March Madness in the classroom. Based on personal observations, for some students, maintaining their undivided attention to their studies, whether it is in class or outside of class is challenging over those several weeks in March. Anecdotally, significant distractions in the classroom have been observed, whether it be students slyly watching live streams on a mobile device, reviewing brackets, or skipping class and laboratory periods entirely.

Use of March Madness tournament brackets and teaching in the classroom has been reported (Doyne and Schulten, 2010). Similarly, an activity was designed for the Landscape Plants II course at KSU called Plant Madness. This game was modeled after the industry game, Shrub Madness, by Proven Winners Color 
Choice (Proven Winners, Sycamore, IL), which is also based on the NCAA March Madness. One objective of the Plant Madness game was to expose and provide additional, active learning opportunities for students to recognize and be aware of new plant selections and cultivars in the industry, or other important species that may not be so new, that are not covered in the class curriculum. Additional activity objectives were to provide an alternative public speaking experience and an opportunity for students to be creative and have fun, while building on the March Madness atmosphere, a significant college experience for many.

\section{Materials and methods}

The Plant Madness activity was implemented in early March in the HORT 375 Landscape Plants II identification course, in $2016(\mathrm{n}=22)$ and $2017(n=22)$. In both years, $93 \%$ of the students were horticulture majors with a program focus in either landscape horticulture or production horticulture. The classes were composed of freshman (16\%), sophomore $(32 \%)$, junior $(43 \%)$, and senior $(9 \%)$ students. The nonmajor students in the class $(\mathrm{n}=3)$ were agriculture education, psychology, or landscape architecture majors, who took the class to fulfill horticulture minor requirements.

ACtivity implementation. The students received a brief overview of March Madness and how to play the game before beginning the activity. The instructor selected plant species and cultivars of plants (trees, shrubs, perennials, annuals, and bulbs) based

Received for publication 4 Dec. 2018. Accepted for publication 13 Feb. 2019.

Published online 25 March 2019

Department of Horticulture and Natural Resources, Kansas State University, Manhattan, KS 66506

This manuscript has been assigned Contribution no. 19-153-J from the Kansas Agricultural Experiment Station. Mention of a trademark, proprietary product, or vendor does not constitute a guarantee or warranty of the product by the authors, Kansas State University, or the U.S. Department of Agriculture and does not imply its approval to the exclusion of other products or vendors that also may be suitable. Publication of this article was funded in part by the Kansas State University Open Access Publishing Fund.

${ }^{1}$ Associate Professor.

${ }^{2}$ Corresponding author. E-mail: ctmiller@ksu.edu.

This is an open access article distributed under the CC BY-NC-ND license (https://creativecommons.org/ licenses/by-nc-nd/4.0/).

https://doi.org/10.21273/HORTTECH04237-18 on recently introduced and popular selections (within the past $\approx 3$ to 5 years) or other plants in the horticulture industry that were not already covered in the course curriculum. The plant species (which could be considered a "team") were printed on slips of paper and put into a hat. Then, to imitate the NCAA tournament Selection Sunday in which teams are formally selected and assigned rankings, students randomly selected their plant out of a hat. After plant selection, students randomly picked another slip of paper from a hat with a preliminary ranking that would serve as their ranking for their plant in the tournament. The instructor entered the plant species into a bracket based according to their rankings and made it available to the class (Fig. 1). Various customizable brackets can be found on the Internet for activity use (e.g., PrintYourBrackets.com, Mansfield, $\mathrm{OH})$. Each student was required to participate in Bracketology and to complete the bracket for the next class period, in which the tournament commenced. To encourage participation, students were offered extra credit for each round advanced. Each student was given a specific picture depicting his or her plant (which could be considered their team logo) and was used throughout the competition. Students were given the option, at any point during the activity, to provide their own photo for the competition.

For each game, the student with the lower-seeded plant species played first. Both students stood in front of the classroom and each competed for up to $2 \mathrm{~min}$. Each student earned points from a group of three referees or judges composed of department graduate students, staff, and faculty. The referees were the same throughout the class tournament. The points scored were based on several criteria, including quality or level of play (e.g., provided solid understanding of plant; provided details; creativity factor), fouls (e.g., provided inaccurate or very general information; did not use full time allotted), and overall performance (e.g., their level of enthusiasm, audience engagement; improvised play was obvious) (Table 1 ). Scores were tallied after the class period and the student with the most points advanced in the tournament and played in the next class period. Results were sent to students after class, so those who advanced could prepare for the next competition round. For the championship match, students in the class who were already eliminated were allowed to score the final two students, in addition to the referee panel. Table 2 summarizes the key steps of implementing the activity.

SuRvey Design AND DATA ANALYSIS. After the championship game of the activity of Plant Madness, a postactivity assessment instrument was administered (Table 3). Along with demographic data, the survey measured self-perceived learning and creativity, using Likert scale questions. In addition, the assessment tool collected general feedback of the Plant Madness activity. Data were analyzed using JMP (version 10; SAS Institute, Cary, NC). A $t$ test data analysis showed that year was not a significant factor and the data were pooled. Summary statistics were compiled for the pooled data.

\section{Results and discussion}

The results of the surveys were positive and insightful. Considering one of the study objectives was to provide additional learning opportunities and exposure to important and new plant selections in the horticulture industry, $93 \%$ of the students reported that the activity assisted them in increasing their awareness of new or recent plant cultivars (Table $3)$. It is important to note that this was based on student perception of learning. No formal assessment was administered to verify or quantify that they learned new cultivars or other specific plant cultivars, not specifically covered in the course. This would be an opportunity for future implementations.

Nearly all of the students enjoyed the activity with nearly a unanimous approval of yes for both years, despite that just over half of the students for each year were not fans of March Madness or were indifferent (Table 3 ). This was encouraging because an initial concern with the activity was that students would not find the plant identification version interesting, due to a lack of interest in the sports version of March Madness. When asked to rate the Plant Madness activity with other class content and 


\section{Team Single Elimination}

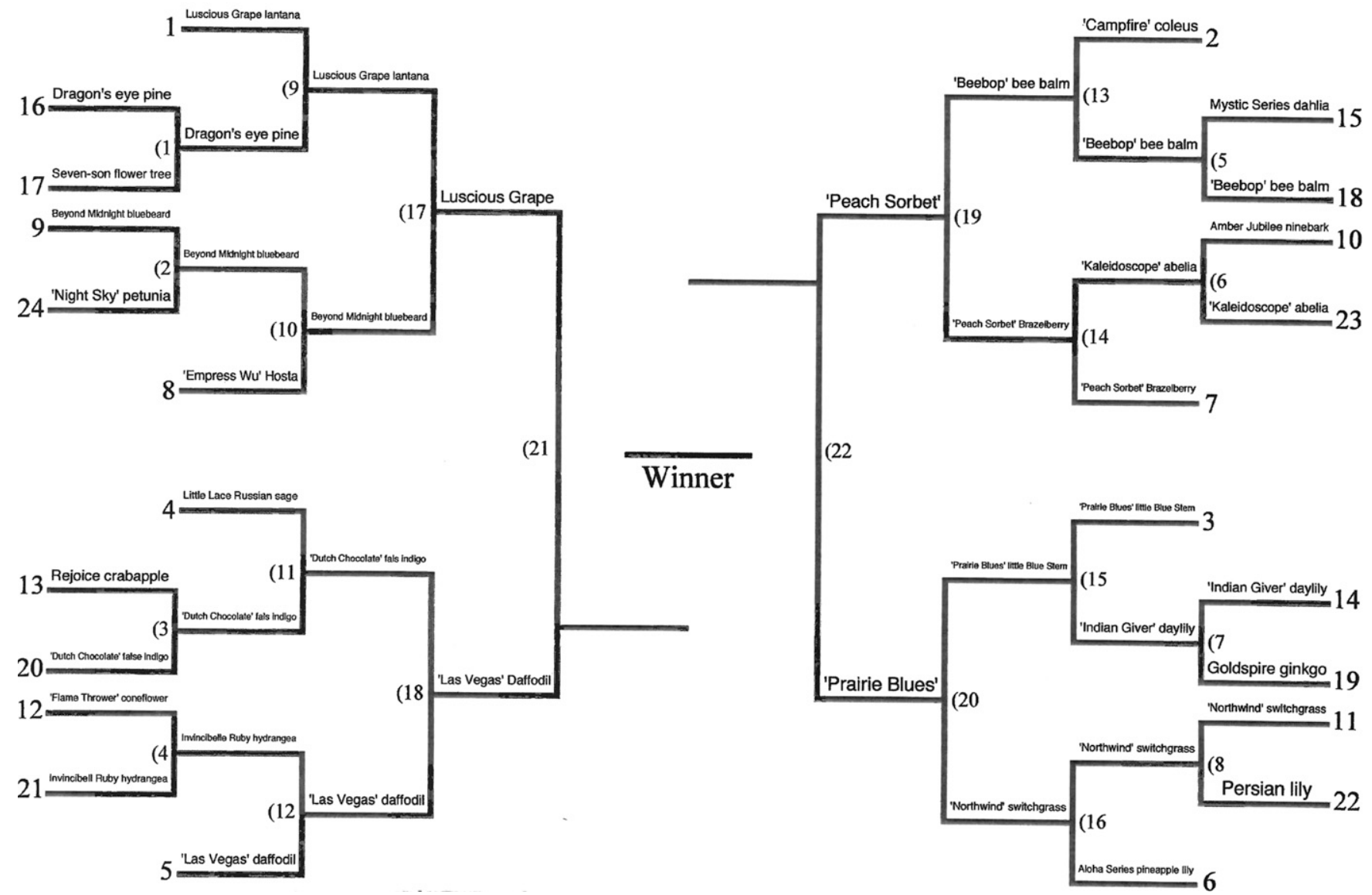

Fig. 1. An example of Plant Madness bracket provided for students for the Plant Madness activity in the HORT 375 Landscape Plants II plant identification course at Kansas State University. Several options for fillable brackets are available online (e.g., PrintYourBrackets.com, Mansfield, $\mathrm{OH}$ ). Plant Madness was a classroom game activity based on the March Madness tournament and Bracketology to provide students an opportunity to learn new and recent cultivars and plant species not specifically covered in the class curriculum.

learning plants, students gave an average rating of 1.8 on a rating scale of $1=$ excellent and $5=$ poor $($ Table 3 ). This further suggests the students liked the activity.

Another concern with this activity was that students would have no interest in competition, particularly in front of their peers. However, based on the postsurvey results, students were comfortable with competition, with an average rating of 1.9 , where $1=$ very comfortable and $5=$ very uncomfortable (Table 3). Competition in games has been shown to enhance learning and motivation of the participants (Cagiltay et al., 2015). It should be noted that the survey question asked about competition and comfort level in general and not specifically how comfortable the student was with competition in the classroom. When asked about their comfort level of giving brief presentations (i.e., public speaking) related to this activity, the average rating was 2.3 , between very comfortable and comfortable (Table 3). Providing opportunities and different styles of public speaking or soft skills (e.g., accurate and effective communication, working well under pressure) are beneficial for professional development and securing employment (Crawford et al., 2011; Easterly et al., 2017).

Many students embraced the competition by creating interactive games and developing poems, whereas other students developed songs, singing them to the rest of the class. Other students only recited facts and figures about their plant. For example, one student created a new song for each of the competitions, which included a beat-box style and drumming. Another student wore costumes that were unique to the plant species and created creative games (e.g., connect-the-dots) that accompanied the play. Other students brought props to support their plant use and its history. The survey asked students to provide comments about what they liked about the activity. One indicated, "It was a fun creative outlet to learn about plants. People got to be goofy and silly and the whole class enjoyed it. I felt it got some people out of their shells and some people thinking about getting out of their shells." Other comments included "It was a fun way to break away from the typical week in this class"; "I loved how excited everyone got about their plants and classmate's (sic) plants. It was a topic of conversation outside class too." Other students remarked, "The creative ways people presented their plants." 
Table 1. Referee or judge scoring guidelines used to evaluate the Plant Madness activity for the HORT 375 Landscape Plants II plant identification course at Kansas State University. Plant Madness was a classroom game activity based on the March Madness tournament and Bracketology to provide students an opportunity to learn new and recent cultivars and plant species not specifically covered in the class curriculum.

\begin{tabular}{l}
\hline Scoring criteria \\
\hline Score each of the players using the following
\end{tabular}

Table 2. Steps used at Kansas State University to implement Plant Madness in the HORT 374 Landscape Plants Course. Plant Madness was a classroom game activity based on the March Madness tournament and Bracketology to provide students an opportunity to learn new and recent cultivars and plant species not specifically covered in the class curriculum.

\section{Class Period 1}

1. Introduction of March Madness (for students not aware) and Plant Madness Activity

2. Students select teams (randomly or by preference)

3. Students randomly assigned team seed rankings

4. Students fill out tournament brackets

5. Demonstration of team competitions

\section{Class Period 2}

1. First round of team play

2. Scores tallied; tournament brackets updated; class notified of results and who plays again

Class Period 3 and on...

1. Subsequent rounds of play until champion is determined

\section{Class Period after Championship}

1. Administer postactivity survey

"It allowed us to try something out of the normal classroom routine. It also allowed students to express creativity and work on presentation skills." Nearly all students recommended the activity for future courses (Table 3).

One of the underlying goals of this activity was to provide an experience that was different from the normal class routine. This was evidenced by the favorable rating they provided compared with other activities they had experienced in the identification courses [e.g., How would you rate the Plant Madness activity, when comparing to other class content of learning different plants? (Table 3)]. Implementing this type of activity can provide added benefits, such as the change of pace and also providing an opportunity for team building or bonding with colleagues [i.e., classmates (Morris, 2018)]. Of the 44 student respondents over both years, 12 students $(27 \%)$ directly indicated in written comments that they appreciated the change of pace and the style of the classroom environment through this activity. Although not specifically asked about fun or enjoyment of this activity, nine different students $(20 \%)$ provided comments in the open-ended questions that specifically mentioned the word "fun." Creating fun spaces can promote student engagement, deep learning, and meaning (Robinson and Kakela, 2006), although the impact of specific types of fun on meaningful student learning outcomes is not well documented (Tews et al., 2015).

Creativity is an important ability for professional success (Jackson, 2004). Creative competency appears to be declining across all ages (Kim, 2011 ) and missing from many educational settings (Kawenski, 1991), whereas creativity is a prominent competency for future leaders (Bronson and Merryman, 2010). Considering horticulture courses provide ample opportunities for developing creative abilities (Pritts and EamesSheavly, 2016), an additional objective for the Plant Madness activity (and in the landscape plants courses in general at KSU) was to promote creativity. When asked to rate their ability to be creative related to this activity, the average response was 1.8 , where $1=$ large extent and $5=$ not at all (Table 3). Interestingly, students also indicated that they could have been more creative (Table 3 ). This suggests that the students recognized the opportunity to be creative, but did not necessarily take advantage of it. Based on instructor observation, the handful of students who strongly disagreed that they could have been more creative could be representative of the group of students who clearly put significant time and effort into the competition.

As with any class activity, there are inherent challenges. One of the major challenges was engagement and getting students to want to participate. Because of the single-elimination format (lose and out), extra credit was awarded to encourage students to want to win and not lose on purpose, thus being eliminated from the tournament and free from further engagement. The class size also can create some challenges. The class sizes described in this article were 
Table 3. Postactivity survey questions used to evaluate the Plant Madness game for the HORT 375 Landscape Plants II plant identification course at Kansas State University. Plant Madness was a classroom game activity based on the March Madness tournament and Bracketology to provide students an opportunity to learn new and recent cultivars and plant species not specifically covered in the class curriculum. ${ }^{\mathrm{z}}$

\begin{tabular}{|c|c|}
\hline Survey questions & $\begin{array}{c}\text { Rating } \\
{[\text { mean }(S D)]}\end{array}$ \\
\hline $\begin{array}{l}\text { How would you rate the Plant Madness activity, when } \\
\text { comparing to other class content of learning different } \\
\text { plants? } \\
\text { (excellent }=1 \text {, above average }=2 \text {, average }=3 \text {, below } \\
\text { average }=4 \text {, poor }=5 \text { ) }\end{array}$ & $1.8(0.7)$ \\
\hline $\begin{array}{l}\text { To what extent were you comfortable giving your brief } \\
\text { presentation in front of the class? } \\
\text { (very comfortable }=1, \text { comfortable }=2 \text {, neither } \\
\text { comfortable or uncomfortable }=3 \text {, uncomfortable }=4 \text {, } \\
\text { very uncomfortable }=5 \text { ) }\end{array}$ & $2.3(1.2)$ \\
\hline $\begin{array}{l}\text { How comfortable are you with competition? } \\
\text { (very comfortable }=1, \text { comfortable }=2 \text {, neither } \\
\text { comfortable or uncomfortable }=3 \text {, uncomfortable }=4 \text {, } \\
\text { very uncomfortable }=5 \text { ) }\end{array}$ & $1.9(1.0)$ \\
\hline $\begin{array}{l}\text { I was able to be creative in this activity. } \\
\text { (to a large extent }=1 \text {, to a moderate extent }=2 \text {, to some } \\
\quad \text { extent }=3 \text {, to a little extent }=4 \text {, not at all }=5 \text { ) }\end{array}$ & $1.8(0.8)$ \\
\hline $\begin{array}{l}\text { I could have been more creative in this activity. } \\
\text { (strongly agree }=1 \text {, agree }=2 \text {, neither agree or disagree }= \\
\quad 3 \text {, disagree }=4 \text {, strongly disagree }=5 \text { ) }\end{array}$ & $3.8(1.2)$ \\
\hline Did you like this class activity? & Respondents (\% \\
\hline $\begin{array}{l}\text { Yes } \\
\text { No } \\
\text { Indifferent }\end{array}$ & $\begin{array}{l}97.7 \\
0 \\
2.3\end{array}$ \\
\hline Are you a fan of March Madness—the sports version? & \\
\hline Yes & 43.2 \\
\hline No & 27.3 \\
\hline Indifferent & 29.5 \\
\hline Would you recommend doing this activity again? & \\
\hline Yes & 95.5 \\
\hline No & 4.5 \\
\hline Maybe & 0 \\
\hline $\begin{array}{l}\text { Do you think that this activity helped you with increasing } \\
\text { your awareness of new or recent plant cultivars? }\end{array}$ & \\
\hline Yes & 93.2 \\
\hline No & 2.3 \\
\hline Indifferent & 4.5 \\
\hline
\end{tabular}

What did you LIKE about this activity?

What did you DISLIKE about this activity?

Anything YOU would do different if you were to do this activity again?

Additional comments?

${ }^{\mathrm{z}}$ The activity was implemented for 2 years, Spring 2016 and 2017. Data were analyzed using a $t$ test and no significant difference was observed between years. Thus, the data were pooled $(n=44)$. about ideal. Smaller class sizes could prove to be a challenge, from the standpoint of a single-elimination bracket and competition. Larger class sizes could be beneficial, as students could be grouped together to form a multimember team. The other major consideration is the scoring and awarding of points. Some students indicated that they thought the scoring became more of a popularity contest. This is conceivable, as some students participate or put forth more effort and subsequently, advance in the tournament. Ideally, students who do well will promote other students to increase or enhance their participation and performance. In addition, conducting or demonstrating how the activity is implemented is beneficial, to give students an idea of the tournament. One other concern would be the activity timeline. It is critical that the competition does not continue for a substantial period; for example, not longer than the actual NCAA March Madness tournament. In the open-ended questions, a few students noted that the game continued on longer than necessary. Thus, this can be an intense activity, much like the NCAA March Madness tournament.

\section{Conclusion}

Overwhelmingly, students enjoyed the activity, as evidenced by the evaluative survey and the direct feedback. Students appreciated the break from the typical daily activities. Moreover, students who participated in the activity wanted to participate in the following year's competition. This activity provided students an opportunity to enhance and practice their public speaking skills, in a slightly different format. Students also refined their skills to identify and present critical information in a prompt, timely, intriguing, and engaging way (e.g., an elevator speech).

The activity provided students an outlet to be creative, although not all students took advantage of the opportunity. Participants enjoyed the different levels of creativity, including the songs, games, and role-playing some demonstrated during the activity. The activity left a strong enough impression that one student discussed the activity with a representative from Proven Winners (and Shrub Madness). It led to an industry-wide promotion of a university Shrub Madness 
edition in Spring 2018. Students and schools competed for the championship, including a scholarship, plants, and other prizes.

Plant Madness has the potential to be used in many different ways within a given class and institution. Students suggested increasing roleplaying and use of props (e.g., buzzers, scoreboards, referees, whistles) to make the tournament even more authentic. The opportunity also exists to implement the activity across institutions. The competitive activity could be expanded to include more assessment and evaluation of curriculum in the course, in greater detail than described here.

\section{Literature cited}

Bronson, P. and A. Merryman. 2010. The creativity crisis. 20 Sept. 2018. <https:// www.newsweek.com/creativity-crisis$74665>$.

Bukszpan, D. 2015. Guess how much money employers lose during March Madness. 21 Sept. 2018. <https:// fortune.com $/ 2015 / 03 / 13 / \mathrm{march}$ madness-employers-lost-productivity/ $>$.

Cagiltay, N.E., E. Ozcelik, and N.S. Ozcelik. 2015. The effect of competition on learning in games. Comput. Educ. $87: 35-41$.

Crawford, P., S. Lang, W. Fink, R. Dalton, and L. Fielitz. 2011. Comparative analysis of soft skills: What is important for new graduates? Assn. Public Land-grant Univ., Washington, DC.
Deeter, L. 2003. Incorporating student centered learning techniques into an introductory plant identification course. North Amer. College Teachers Agr. 47:47-52.

Doyne, S. and K. Schulten. 2010. March Madness: Using tournament brackets to debate academic questions. 24 Sept. 2018. <https://learning.blogs.nytimes. com $/ 2010 / 03 / 19 /$ march-madnessusing-tournament-brackets-to-debateacademic-questions $/>$.

Easterly, R.G., III., A.J. Warner, B.E. Myers, A.J. Lamm, and R.W. Telg. 2017. Skills students need in the real world: Competencies desired by agricultural and natural resources industry leaders. J. Agr. Educ. 58:225-239.

Geiling, N. 2014. When did filling out a March Madness bracket become popular? 18 Nov. 2018. <https://www. smithsonianmag.com/history/whendid-filling-out-march-madness-bracketbecome-popular-180950162/>.

Jackson, N. 2004. Creativity in higher education. 20 Sept. 2018. <https:// imaginativecurriculumnetwork.pbworks. $\operatorname{com} / \mathrm{f} / \mathrm{Im}$ aginative + Curriculum + Network + Information + Note +2004 . pdf>.

Kawenski, M. 1991. Encouraging creativity in design. J. Creative Behavior 25: 263-266.

Kim, K.H. 2011. The creativity crisis: The decrease in creative thinking scores on the Torrance tests of creative thinking. Creat. Res. J. 23:285-295.
Morris, C. 2018. The average worker will spend six hours watching March Madness at work. 24 Sept. 2018. <https:// fortune.com $/ 2018 / 03 / 01 / \mathrm{march}$ madness-2018-worker-productivity/>.

Pritts, M. and M. Eames-Sheavly. 2016. Fostering creativity in the horticulture classroom. HortTechnology 26:358364.

Robinson, C.F. and P.J. Kakela. 2006. Creating a space to learn: A classroom of fun, interaction, and trust. College Teach. 54:202-207.

Smith, A.A. and A.D. Smith. 2011. March Madness, office gambling, and workplace productivity issues: An empirical study. Sport Business Mgt. Intl. J. 1:196-206.

Smith, A.A., A.D. Smith, and O.F. Offodile. 2011. March Madness and perceived influences on workplace productivity by business professionals: An exploratory study. Sport Business Mgt. Int. J. 1:23-45.

Tews, M.J., K. Jackson, C. Ramsay, and J.W. Michel. 2015. Fun in the college classroom: Examining its nature and relationship with student engagement. College Teach. 63:16-26.

Wilco, D. 2019. What is March Madness: The NCAA tournament explained. 20 Nov. 2018. <https://www.ncaa.com/ news/basketball-men/bracketiq/2018$10-10 /$ what - march-madness-ncaatournament-explained $>$. 